\title{
Legislating intersex equality: building the resilience of intersex people through law
}

\author{
Fae Garland ${ }^{1 \dagger}$ and Mitchell Travis ${ }^{2 *}$ \\ ${ }^{1}$ School of Law, University of Manchester, Manchester, UK and ${ }^{2}$ School of Law, University of Leeds, Leeds, UK \\ *Corresponding author. Email: m.travis@leeds.ac.uk
}

(Accepted 11 March 2018)

\begin{abstract}
This paper presents the findings from the first qualitative study to consider the relationship between intersex experience and law, representing a significant contribution to a currently under-researched area of law. Since 2013 there has been a global move towards the legal recognition of intersex, with Australia, Germany and Malta all using different techniques to construct and regulate intersex embodiment. This paper is the first to compare and problematise these differing legal approaches in the legal literature. In doing so it demonstrates that many of these approaches are grounded in ideas of formal equality that lead to the entrenchment of vulnerability and fail to build resilience for the intersex community. Through engagement with the intersex community a more contextual account of substantive equality is enabled, encouraging new approaches to law and social justice. Our qualitative study revealed that prevention of non-therapeutic medical interventions on the bodies of children was understood to be the key method to achieving equality for intersex embodied people. Whilst this is the cornerstone of intersex-led legislative reform, such an approach necessitates support through a mixture of formal and substantive equality methods such as anti-discrimination law, education and enforcement procedures. This paper concludes by offering a series of recommendations to legislators capable of enabling substantive intersex equality.
\end{abstract}

Keywords: intersex; embodiment; vulnerability; substantive equality; formal equality

\section{Introduction}

The last 20 years has seen a global increase in the legal recognition of intersex. ${ }^{1}$ Whilst a number of qualitative studies have examined the experiences of intersex persons in relation to medicine, this paper offers findings from the first study to examine the practical impact that law has had on the lives and experiences of intersex embodied people. As such, this paper offers new empirical evidence

\footnotetext{
${ }^{\dagger}$ This project was made possible by funding from the Socio-Legal Studies Association small grants scheme and the generosity and vision of our participants. We would also like to thank Anne Barlow, Neil Cobb, Georgiann Davis, Sarah Devanney, Chris Dietz, Sam Lewis, Michael Thomson and Julie Wallbank for their insightful comments on an earlier version of this paper. All mistakes remain our own.

${ }^{1}$ In 2003, Australia's Department for Foreign Affairs and Trade recognised a third marker on passports. Since then, different jurisdictions have brought in legislative provisions designed to offer greater protections to intersex: see eg South Africa's Judicial Matters Amendment Act 2005; Scotland's Offences (Aggravation by Prejudice) (Scotland) Act 2009; Australia's Sex Discrimination Amendment (Sexual Orientation, Gender Identity and Intersex Status) Act (Cth) 2013; Germany's Gesetz zur Änderung personenstandsrechtlicher Vorschriften (Personenstandsrechts-ÄnderungsgesetzPStRÄndG) 2013; Jersey's Discrimination (Sex and Related Characteristics) (Jersey) Regulations 2015; Finland's laki miesten ja naisten välisestä tasa-arvosta/lag om jämställdhet mellan kvinnor och män, Act no 609/1986; Bosnia-Herzegovina's Law on the Prohibition of Discrimination 2009; and Malta's Gender Identity, Gender Expression and Sex Characteristics Act 2015 (GIGESC). Iceland considered introducing legislative protections similar to the Maltese approach in 2017. This was rejected by parliament in 2018 .
}

(c) The Society of Legal Scholars 2018 
to an under-researched area. While the legal trend towards recognising intersex embodied people ${ }^{2}$ is still in its infancy, this movement is gaining significant momentum and a growing number of states are debating the possibility of legislative reform. Such discussions inevitably draw upon the experiences of other legal systems. However, many of these legal frameworks have yet to be critically evaluated in the academic literature and consequently it is unclear how far, if at all, these different approaches have actually responded to the needs and claims of the intersex community. Indeed, legal recognition is not always a liberating experience ${ }^{3}$ and there is a danger that law could actually decrease the resilience of intersex embodied people. ${ }^{4}$ At present, the majority of states do not legally recognise intersex and continue to rely on a medical narrative that prioritises medical intervention to 'normalise' intersex bodies, rendering individuals invisible at the institutional and political levels as well as perpetuating bodily harms. ${ }^{5}$ Such states can be seen as failing to engage with formal or substantive accounts of equality. In contrast, some states such as Germany and Australia have introduced formal equality provisions that focus on status and identity using, for example, third sex/gender markers on official documents and anti-discrimination law in an attempt to level the social playing field. ${ }^{6}$ Others, such as Malta, have adopted a more holistic approach to legal reform based on a substantive equality model that concentrates on protecting the bodily integrity of intersex children by prohibiting unnecessary surgeries. ${ }^{7}$ This paper considers contemporary legal responses to intersex and the critique of these reforms from semi-structured interviews with members of the intersex community. In doing so, the authors use vulnerability theory to expose how law's continuing ignorance around sex as a spectrum, and latterly its focus on formal equality, works to disenfranchise intersex embodied people. Moreover, vulnerability theory is used to argue that the state has a responsibility to redress ongoing social and legal inequalities that intersex embodied people face. ${ }^{8}$ Accordingly, the paper sets an agenda for legislative reform informed by the needs and desires of the intersex community.

\footnotetext{
${ }^{2}$ The terminology for intersex is contested. See eg G Davis Contesting Intersex: The Dubious Diagnosis (New York: New York University Press, 2015). The authors use the term 'intersex embodiment' as it highlights the material and biological basis of intersex as well as how intersex is socially constructed through institutions such as medicine, family and/or law. For the authors, embodiment takes place at the intersection of the material, the discursive and the institutional. This tripartite lens allows us to consider how the materiality of the body is situated, understood and constructed. The impacts of these constructions on the body make it ultimately impossible to understand materiality outside of the confines of discourse and institutions. Such an analysis therefore pays attention to medical and legal legacies around intersex but does not privilege them or attempt to pathologise intersex experience. Consequently, this paper does not use the medical term 'disorders of sex development' (DSD) or 'differences of sex development' due to their privileging of medical power/knowledge. For more discussion of embodiment see M Travis 'The vulnerability of heterosexuality: consent, gender deception and embodiment' (2018) Social and Legal Studies; and C Dietz 'Governing legal embodiment: on the limits of self-declaration' (2018) Feminist Legal Studies 1.

${ }^{3}$ A Kolbe 'Intersex, a blank space in German law?' in M Holmes (ed) Critical Intersex (Farnham: Ashgate, 2009) p 147.

${ }^{4} \mathrm{C}$ Mackenzie 'The importance of relational autonomy and capabilities for an ethics of vulnerability' in C Mackenzie, W Rogers and S Dodds (eds) Vulnerability: New Essays in Ethics and Feminist Philosophy (Oxford: Oxford University Press, 2014) p 33; J Wallbank and J Herring 'Introduction: vulnerabilities, care and family law' in J Wallbank and J Herring (eds) Vulnerabilities, Care and Family Law (Oxford: Routledge, 2013) p 1.

${ }^{5} \mathrm{M}$ Travis 'Accommodating intersexuality in European Union anti-discrimination law' (2014) 21(2) European Law Journal 180 at 182.

${ }^{6}$ Germany's Gesetz zur Änderung personenstandsrechtlicher Vorschriften (Personenstandsrechts-ÄnderungsgesetzPStRÄndG) 2013 states, $\$ 22$ Abs 3: '(3) If the child can be assigned to neither the female nor the male sex, then the child must be entered into the register of births without such a specification'. A recent decision by the Bundesverfassungsgericht went beyond this to highlight a need for the positive recognition of a third gender option (Order of 10 October 2017 - 1 BvR 2019/16). Australia's Department for Foreign Affairs and Trade recognises a third marker on passports, while the Sex Discrimination Amendment (Sexual Orientation, Gender Identity and Intersex Status) Act (Cth) 2013 inserted section 5(c) into the Sex Discrimination Act 1984 to recognise intersex as a possible ground for anti-discrimination.

${ }^{7}$ See eg Malta's GIGESC.

${ }^{8}$ MA Fineman 'The vulnerable subject and the responsive state' (2010) 60 Emory LJ 251 at 268, and 266 fn 53.
} 


\section{Intersex embodiment and entrenched inequalities}

In recent history, intersex embodied people have largely been absent from legal concern and instead constructed as a medical 'problem', forestalling questions of identity and legal protection. Consequently, intersex bodies have been regulated informally by the medical profession which has constructed a biomedical narrative of intersex through a catalogue of sex development 'disorders' and 'diseases' that (despite their often benign nature) are portrayed as requiring medical intervention. ${ }^{9}$ This narrative has traditionally embedded these issues within the private sphere and outside of public concern and thus state responsibility. Predominantly, the medical goal has been to 'normalise' or 'fix' these bodies through interventions to ensure they adhere to the sex binary. Surgeons routinely surgically alter children born with ambiguous genitalia, arbitrarily allocating them as male or female, ${ }^{10}$ which typically results in a lifetime of surgical treatments and hormonal dependency to maintain their allocated sex. ${ }^{11}$ These interventions are usually non-therapeutic, having no medical benefit, and yet can lead to lifelong physical problems. Thus, such practices have been condemned by advocacy groups, human rights organisations and supranational bodies including the UN and the Council of Europe. ${ }^{12}$ Surgical interventions tend to occur soon after the child is born ${ }^{13}$ which, combined with the culture of secrecy that accompanies intersex conditions, has led to an erasure of intersex in political and legal discourse and often within the familial institution. Little is known about intersex outside of the medical profession, and the shame and stigma attached to a 'disorders of sex development' label prevents families and individuals from speaking out. Indeed many families go to great lengths to hide such a 'diagnosis'. ${ }^{14}$

Given law's role in determining who does and does not legitimately participate in society, its failure to recognise intersex people has had profound implications. Legal silence effectively legitimises the medical account of intersex as a purely material concern, permits attempts to 'normalise' these bodies and enables their social or cultural erasure. Thus, law aligns itself with the biomedical discourse of intersex depicting such bodies as deviant or unruly and in need of taming. ${ }^{15}$ In doing so, law reaffirms a binary understanding of sex and consequently places intersex individuals outside of the scope of law; unable to participate in or to challenge the dominant biomedical narrative. Law's silence is therefore not neutral; rather it perpetuates the existence of a striking power imbalance between intersex people, their families and the medical profession. In terms of vulnerability analysis, the medical profession also needs to be understood in relation to its embeddedness and context. For the purposes of this paper, this embeddedness needs to be understood in terms of the binary sex model. The history of the medical profession is tied to notions of binary sex which it reinforces and legitimises (through the privileging of scientific knowledge) in order to maintain its own epistemic primacy. Treatment and diagnoses, therefore, must be understood through a general cultural, social and state acceptance of sex as binary. Within this context medical knowledge that reaffirms contemporary cultural norms is

\footnotetext{
${ }^{9}$ Davis, above $\mathrm{n} 2$.

${ }^{10}$ See eg A Fausto-Sterling Sexing the Body: Gender Politics and the Construction of Sexuality (New York: Basic Books, 2000).

${ }^{11} \mathrm{JA}$ Greenberg Intersexuality and the Law: Why Sex Matters (London: New York University Press, 2012) p 5.

${ }^{12}$ Greenberg, above n 11, pp 5-6. Problems can include osteoporosis, infection, scarring, incontinence and sexual functioning as well as psychological trauma. The UN has deemed such medical interventions to be 'harmful practices', 'violation[s] of integrity' and 'inhuman treatment' UN Human Rights Council, Report of the Special Rapporteur on Torture and Other Cruel, Inhuman or Degrading Treatment or Punishment, Juan E Méndez, 1 February 2013, A/HRC/22/53, at para 77, available at https://www.ohchr.org/Documents/HRBodies/HRCouncil/RegularSession/Session22/A-HRC-22-53-Add4_EFS.pdf (last accessed 16 July 2018). See also Council of Europe Parliamentary Assembly, Resolution 1952 Children's right to physical integrity, 2013, available at http://assembly.coe.int/nw/xml/XRef/Xref-XML2HTML-en.asp?fileid=20174\&lang=en (last accessed 16 July 2016 ).

${ }^{13}$ Typically these interventions are at birth, before sex must be formally registered. In England and Wales the Births and Deaths Registration Act 1953, s 2, provides that the sex of the child (and other details) must be given to the Registrar of births and deaths within 42 days.

${ }^{14}$ Davis, above $\mathrm{n} 2$.

${ }^{15}$ Travis, above n 5, at 182; I Karpin and R Mykitiuk 'Feminist legal theory as embodied justice' in MA Fineman (ed) Transcending the Boundaries of Law: Generations of Feminism and Legal Theory (Oxford: Routledge, 2011) p 115.
} 
privileged over the lived experiences of individuals who do not conform to this binaristic model, who are routinely characterised as a very small, unrepresentative minority. ${ }^{16}$ Moreover, such an analysis is attentive to the pressures that medical professionals face from other institutions. The familial institution, for example, exerts considerable pressure on medical professionals to produce a 'normal' child in order to create certainty and stability for their own normative worldview. As a result, decision making in this field is a complex entanglement of cultural and social norms, scientific knowledge claims and medical pragmatism.

Against this background, law is often seen as a tool of empowerment, giving centrality to the voice, desires or best interests of the child. ${ }^{17}$ Law is capable of levelling the playing field; and therefore the gradual legal recognition of intersex potentially indicates a shift in power and knowledge whereby intersex individuals can be framed in both medical and legal terms. ${ }^{18}$ Yet it is unclear how far, if at all, increasing juridicial responses to intersex are actually challenging this dominant medical narrative. Indeed, differing legal constructions of intersex can entrench vulnerability rather than enhance resilience. This article seeks to examine the efficacy of current approaches through interviews with intersex people in order to ascertain methods of enhancing their resilience through law and other institutions.

\section{Vulnerability theory and intersex legal reform: from formal to substantive equality}

Martha Fineman's work on vulnerability is a useful framework through which to examine current state responses to intersex. Vulnerability theory positions individuals in terms of both their material embodiment and embeddedness within social institutions and relationships. ${ }^{19}$ This theory starts from the position that we are all vulnerable. This vulnerability is both universal (we are all susceptible to disease or disaster) and particular (there may be differences in access to healthcare, or home insurance that exacerbate or mitigate these vulnerabilities). As vulnerability can never be eradicated, Fineman suggests that approaches to vulnerability should be understood in terms of resilience. As such, her work is useful for thinking through the ways in which the state and other institutions can increase or reduce individual and group resilience. For vulnerability theorists, the universal nature of vulnerability also necessitates a new relationship with the state. In contrast to neoliberal approaches that have seen the state withdraw from intervention on the basis of maximising autonomy, a vulnerability analysis highlights that such neoliberal understandings are rooted within a model of formal equality which perpetuates existing levels of social inequality. Approaches grounded in formal equality tend to frame injustice in terms of recognition rather than redistribution. ${ }^{20}$ Such approaches often fail to address the underlying causes of inequality instead focusing their efforts towards antidiscrimination. ${ }^{21}$ Moreover, Fineman's vulnerability thesis exposes the liberal autonomous subject as a myth ${ }^{22}$ and further highlights the danger of formal equality, as it ignores context and the material inequalities that may exist between individuals. A vulnerability analysis demands the state be responsive in a manner that is attentive to substantive equality. As Fineman writes:

... the idea of the vulnerable subject was largely prompted by dissatisfaction with the equality approach and the limited ability of equality theory ... to address the persistent and growing

\footnotetext{
${ }^{16}$ SF Ahmed et al 'Society for Endocrinology UK guidance on the initial evaluation of an infant or an adolescent with a suspected disorder of sex development' (2016) 84(5) Clinical Endocrinology 771.

${ }^{17} \mathrm{~J}$ Bird 'Outside the law: intersex, medicine and the discourse rights' (2016) 12 Cardozo Journal of Law and Gender 65 at 66.

${ }^{18}$ Ibid, at 67.

${ }^{19} \mathrm{M}$ Fineman 'The vulnerable subject: anchoring equality in the human condition' (2008) 20 Yale Journal of Law and Feminism 1; Fineman, above n 8; M Fineman "Elderly" as vulnerable: rethinking the nature of individual and societal responsibility' (2012) 20 The Elder Law Journal 101; M Fineman 'Vulnerability, resilience, and LGBT youth' (2014) 23 Temple Political \& Civil Rights Law Review 307.

${ }^{20} \mathrm{~N}$ Fraser in N Fraser and A Honneth Redistribution or Recognition? A Political-Philosophical Exchange (London: Verso, 2003).

${ }^{21}$ As shall be discussed in the context of intersex, such approaches fail to engage with the main concerns of the intersex community. These approaches may be better, however, than a UK approach which has made no attempt at equality.

${ }^{22}$ Fineman (2008), above n 19.
} 
structural and political inequalities in ... society ... Formal equality ... leaves undisturbed - and may even serve to validate - existing institutional arrangements that privilege some and disadvantage others ... Formal equality does not challenge existing allocation of resources and power. ${ }^{23}$

Vulnerability is therefore an important device to 'examine hidden assumptions and biases folded into legal ... practices' and demands that the state has a responsibility to redress existing social and legal inequalities. ${ }^{24}$ Part of this responsibility necessitates the state to actively monitor institutions in terms of their success at promoting resilience and to intervene where they are not operating in an egalitarian manner. ${ }^{25}$

Yet, formal equality is becoming the dominant method employed by states to address the needs of intersex embodied people. Largely, legislative responses can be divided into three themes: nonresponsive; status-based; and holistic. While the majority of states (including the UK) are nonresponsive, maintaining this medical/individual power imbalance, the most common state response has been to recognise intersex 'identity' within law either by integrating intersex as a 'protected characteristic' within anti-discrimination law and/or by using third markers to signify an intersex 'status'. Australia, ${ }^{26}$ for example, has specific anti-discrimination legislation, which recognises intersex status as a protected characteristic (alongside characteristics generally appertained/imputed to persons of intersex status). Additionally, some Australian states have allowed birth certificates to omit sex where the sex of a child has been indeterminate, ${ }^{27}$ and in 2003 , Australia was the first country to allow ' $\mathrm{X}$ ' markers on passports for intersex individuals. This was expanded in 2011 to include all those of indeterminate sex. ${ }^{28}$ South Africa ${ }^{29}$ and Jersey, ${ }^{30}$ have specific anti-discrimination legislation that includes 'intersex' within the protected characteristic of 'sex', Finland ${ }^{31}$ includes 'gender features of the body' within the protected characteristics of 'gender identity and gender expression' and Greece and Bosnia-Herzegovina ${ }^{32}$ prohibit discrimination and hate crimes made on the basis of 'sex characteristics'. Scotland offers more limited recognition not within anti-discrimination law, ${ }^{33}$ but through an extension of 'hate crime' legislation. ${ }^{34}$ Germany, although having no specific anti-discriminatory provisions, allows for third markers on birth certificates to be used for intersex embodied children ${ }^{35}$

\footnotetext{
${ }^{23}$ Fineman (2012), above n 19, at 131-132.

${ }^{24}$ Fineman, above n 8, at 266 fn 53.

${ }^{25} \mathrm{M}$ Fineman 'Equality, autonomy, and the vulnerable subject in law and politics' in M Fineman and A Grear (eds) Vulnerability: Reflections on a New Ethical Foundation for Law and Politics (Farnham: Ashgate, 2013) p 1 at p 19 fn 3.

${ }^{26}$ See $n 8$.

${ }^{27}$ This has occurred in Victoria and New South Wales. Eg in Norrie v NSW Registrar of Births, Deaths and Marriages [2013] NSWCA 145 the High Court of New South Wales held that the registrar could record the sex of someone as 'nonspecific' rather than 'male' or 'female'. Here, the Court acknowledged that: '... [n] ot all human beings can be classified by sex as either male or female ...'.

${ }^{28}$ See https://www.passports.gov.au/passportsexplained/theapplicationprocess/eligibilityoverview/Pages/changeofsexdoborpob.aspx (last accessed 10 July 2018). Individuals have to provide medical evidence of their intersex status. The right to a non-binary passport has also recently been won in the US, see http://www.lambdalegal.org/in-court/legal-docs/zzyym_co_ 20161122_order (last accessed 10 July 2018).

${ }^{29}$ Section 16 Judicial Matters Amendment Act 2005 amended the Promotion of Equality and Prevention of Unfair Discrimination Act (2000) so that s 1 now includes intersex within the protected characteristic of sex.

${ }^{30}$ The Discrimination (Sex and Related Characteristics) (Jersey) Regulations 2015 amended the Discrimination (Jersey) Law 2013 to include intersex within the definition of sex.

${ }^{31}$ Section 3(5) laki miesten ja naisten välisestä tasa-arvosta/lag om jämställdhet mellan kvinnor och män, Act no 609/1986, Finland's Gender Equality Act was amended in 2015 to extend protections to intersex individuals.

${ }^{32}$ Article 2 Law on the Prohibition of Discrimination 2009 was amended in July 2016.

${ }^{33}$ Scotland's anti-discrimination law is governed by the Equality Act 2010, which does not recognise intersex as a protected characteristic. This Act also covers England and Wales.

${ }^{34}$ Section 2 Offences (Aggravation by Prejudice) (Scotland) Act 2009. Rather problematically, however, intersex falls under the definition of 'transgender identity' under s 8(a).

${ }^{35}$ See $n 7$.
} 
and it, alongside an increasing number of other states, permits individuals (including intersex embodied people) to choose a third marker on passports. ${ }^{36}$

While there are a variety of ways through which a state may formally embed 'intersex', unpicking the effect that this will have on the individual/medical professions' power imbalance is complex. Status-based approaches are focused on formal rather than substantive equality; the mechanisms employed, like anti-discrimination law, do not attempt to redress substantive inequalities as they do not directly challenge the authority of the medical profession. Instead, they formally recognise intersex as a legal category rather than redressing the resilience of these individuals. Anti-discrimination law may go further than third markers to offer intersex individuals basic protections within the workplace and beyond, but it is not designed to prohibit medical interventions and thus it is unclear how far such provisions will shift power away from the medical jurisdiction towards intersex individuals. Moreover, as most of these provisions are based on the existence of an intersex status, they inevitably require some affirmative action through self-identification by the individual (or indeed their parents) ${ }^{37}$ to 'activate' their legal 'intersex' identity. ${ }^{38}$ Thus, the individual (or parents) must openly challenge the biomedical discourse and the culture of erasure themselves before legal provisions based on status are able to take effect. At the same time institutions incentivise individuals (and parents) to conform to heteronormative and binary-led values and make it exceptionally difficult to make choices outside of these constraints. ${ }^{39}$ Only Australia has a broader approach that not only prohibits discrimination on the grounds of intersex status, but also on the grounds of characteristics generally imputed to intersex individuals. ${ }^{40}$ This broader approach may allow for a richer variety of possibilities in the formation and defence of their legal identity. Nonetheless, there is still the real possibility that legal recognition of intersex status may empower in the long-term: the creation of a legal space will increase the visibility of intersex individuals at the institutional and discursive levels. Bird, for example, argues that such legal acknowledgement of intersex will not only create greater space for political negotiation, but it may create a social space for individuals to participate in if they so wish. ${ }^{41}$ This may in turn give individuals a legal platform to legitimately challenge the authority of the medical profession and fundamentally instigate broader social changes that redress substantive inequalities.

While formal equality approaches are becoming the favoured state solution, at the time of writing only one state, Malta, has adopted a 'holistic' approach ${ }^{42}$ that responds to the most important agenda issue for the intersex community: Malta specifically outlaws unnecessary sex assignment treatment and surgery on intersex minors through the Gender Identity, Gender Expression and Sex Characteristics Act 2015 (GIGESC). Section 15 GIGESC defers sex reassignment surgery and surgical interventions on sex characteristics until the individual is able to make an informed choice. Section 15 (2) recognises there may be some exceptional circumstances whereby surgery takes place where a minor is unable to provide consent, but states that 'medical intervention which is driven by social factors without the consent of the individual concerned will be in violation of this Act'. This form of legal governance directly challenges the medical jurisdiction over intersex bodies as it allows individuals rather than their families and doctors to make 'decisions affecting their own bodily integrity and physical autonomy'. ${ }^{43}$ Additionally, Malta permits individuals to self-determine their own gender identity

\footnotetext{
${ }^{36} \mathrm{New}$ Zealand also allows ' $\mathrm{X}$ ' on passports for those of 'indeterminate/unspecified' sex, however, there is no mention of 'intersex' and applicants are classified as 'transgender applicants', thus it is questionable how far intersex individuals would be able to use this third marker. See https://www.passports.govt.nz/transgender-applicants (last accessed 10 July 2018). Outside of the West, Bangladesh allows a third marker for its trans, intersex or third-gender individuals.

${ }^{37}$ In Germany, for example, the decision to not assign male or female to an intersex infant may rest with the parents.

${ }^{38}$ Greenberg, above n 11, p 49.

${ }^{39}$ See eg Travis, above n 2.

${ }^{40}$ Sex Discrimination Act 1984, s 5C.

${ }^{41}$ Bird, above $\mathrm{n} 17$, at 67.

${ }^{42}$ Since the interviews Portugal has introduced Law No 75/XIII/2 2018 prohibiting non-therapeutic medical interventions on intersex children.

${ }^{43}$ GIGESC, Objects and Reasons.
} 
(without medical evidence); ${ }^{44}$ extends its 'hate crime' legislation to incorporate sex characteristics and also sets out sex characteristics as a protected category within its anti-discrimination law. ${ }^{45}$ Thus Malta has an expansive approach that decouples legal regulation of intersex embodiment from the biomedical narrative and instead attempts to redress substantive inequalities. Indeed the major purpose of these reforms was not only to recognise intersex embodied people, but also to attempt to integrate intersex embodied people as full participants within Maltese society.

This paper evaluates the implications of these different approaches in practice, and considers whether the more formal-based mechanisms have failed to increase the resilience of intersex persons. To do so this paper presents findings from an empirical study that examined the ways in which intersex people are governed.

\section{Methodology}

This was a qualitative study designed to produce an in-depth and detailed examination of legal reform in the area of intersex equality. The authors conducted 17 semi-structured interviews with intersex rights activists between August 2014 and August 2016 of whom 14 identified as intersex. ${ }^{46}$ Although this sample is therefore small, it is nevertheless appropriate for such a qualitative study. ${ }^{47}$ Moreover, the cultural and medical invisibility of intersex makes this group very difficult to access, particularly when constrained by time and resources. Thus the authors used purposive sampling as they wanted to interview individuals who were likely to be aware of global developments in intersex rights, namely activists, ${ }^{48}$ and suitable participants were identified and contacted through organisational websites and also by snowballing. The sample includes individuals from non-responsive states like the UK, Denmark, USA and Sweden; status-based states like Australia and Germany; and holistic states such as Malta and Iceland. Whilst individuals were from a range of cultural and social backgrounds and thus do not represent the views of the entire intersex populace, the close interconnectedness of the international intersex activist community meant participants were aware of various global legal developments. Thus, individuals were helpfully able to draw on the practical experiences within their own cultural, social and legal contexts as well as offer comparisons with alternative approaches. Perhaps due to the method of participant recruitment the study does not contain the views of activists or intersex people from the global south. This may have important ramifications on the ability to extrapolate from this data in a number of different contexts. Certainly, this is an avenue worthy of future exploration. ${ }^{49}$

Given the sensitive nature of this topic, the authors ensured that the study complied with the SLSA's ethical guidelines by using information sheets to ensure consent was fully informed,

\footnotetext{
${ }^{44}$ GIGESC, s 4 allows individuals to change official records of their gender without any requiring medical evidence.

${ }^{45}$ GIGESC, s 4 allows individuals to request change in first name and recorded gender to reflect self-determined gender. No medical evidence is necessary. Section 10(3) amends Art 83B of the Maltese Criminal Code to include offences motivated on the basis of gender expression and sex characteristics. GIGESC, s 14 prohibits discrimination on the basis of sexual orientation, gender identity, gender expression and sex characteristics' discrimination.

${ }^{46}$ Fourteen were interviewed by telephone, three submitted electronic email responses either because of resources or because they did not want to be interviewed. One telephone interview involved two of the respondents who wanted to be interviewed together.

${ }^{47}$ There is no set minimum for the number of respondents to take place in a qualitative project. F Garland 'Section 15 Property (Relationships) Act 1976: compensation, substantive equality and empirical realities' (2014) 3 New Zealand Law Review 355 at 373. See also S Baker and R Edwards 'How many qualitative interviews is enough? Expert voices and early career reflections on sampling and cases in qualitative research' National Centre for Research Methods Review Paper (2012, ESRC).

${ }^{48}$ This term 'activists' also includes support groups and education workers. For a comprehensive explanation of the ways in which activism has developed in the intersex movement see Davis, above n 2; A Dreger and A Herndon 'Progress and politics in the intersex rights movement: feminist theory in action (2009) 15(2) GLQ: A Journal of Lesbian and Gay Studies 199.

${ }^{49} \mathrm{~A}$ few particularly pertinent questions may be how far activists from the global south identify as being part of this 'global community' or are capable of joining such a community and how far their concerns mirror those of activist groups in the global north.
} 
participation was voluntary, anonymous and confidential. ${ }^{50}$ The authors also asked individuals from two independent intersex organisations (one UK-based, the other USA-based) to scrutinise the interview schedule and information sheets. The interviews themselves explored how far these differing types of legal governance increase the resilience of intersex individuals and examined the individual's understanding of and relationship with law. This involved specific questions about the use of antidiscrimination law, third markers on passports and also the prohibition of surgery as well as more general questions relating to the interplay of law and medicine. The data were analysed using thematic analysis $^{51}$ whereby themes were generated against the backdrop of vulnerability theory producing four main substantive themes: intersex concerns, the fallacy of formal equality approaches; the transformative potential of formal equality; and challenging substantive inequality.

The interviewees' responses encouraged us to think more critically about jurisdiction and medical authority and their embeddedness within legal relationships. This creates a point of reflection for developing informed policy and guides responses to these issues at a state level.

\section{Intersex concerns: substantive rather than formal inequalities}

The respondents, unsurprisingly, indicated that many inequalities faced were substantive (embedded, structural and systemic) rather than formal (individual and localised). These inequalities arose out of the medical/individual power imbalance and the medical profession's failure to understand intersex: it attributed intersex characteristics to be biological mistakes rather than 'natural variations'. The consequence of this mistaken categorisation was that the medical interventions used to 'treat' these 'disorders' were considered inappropriate. Nearly all respondents framed cosmetic genital surgeries on children as having no real certifiable benefit and instead often contributing to long-term mental and physical health problems. ${ }^{52}$

... [The Medical profession] changes something which is a natural variation of humanity through to illness. They are created as patients that have a medical problem and they didn't have one in the first place ... (Respondent 7$).^{53}$

... most intersex, at least I know, are very, very traumatised and suffer from physical and psychological harm of these genital surgeries during childhood. (Respondent 5)

Respondents critiqued the lack of long-term follow up studies that track the effect of such medical interventions and called for a stop to these practices and for more research to be collected. ${ }^{54}$

\footnotetext{
${ }^{50}$ The information sheets set out the project's details and contact details of intersex support groups. Participants were made aware that they could withdraw from the process at any time, and all data was anonymised by removing any identifying information. To ensure confidentiality, access to non-anonymised data was limited to the authors. For the Socio Legal Studies Association's Statement of Principles Guiding Empirical Research see http://www.slsa.ac.uk/images/slsadownloads/ethicalstatement/slsa\%20ethics\%20statement\%20_final_\%5B1\%5D.pdf (last accessed 10 July 2018).

${ }^{51}$ This six step process was: (1) to familiarise one's self with the data; (2) generate initial codes; (3) search for themes; (4) review themes; (5) define and name themes; and (6) produce the report: V Braun and V Clarke 'Using thematic analysis in psychology' (2006) 3 Qualitative Research in Psychology 77, 84 and 87.

${ }^{52}$ This evidence has been found elsewhere. See Greenberg, above n 11, pp 21-25; T Jones et al Intersex: Stories and Statistics from Australia (Cambridge: Open Book Publishers, 2016) available at http://interactadvocates.org/wp-content/uploads/2016/ 01/Intersex-Stories-Statistics-Australia.pdf (last accessed 10 July 2018) pp 109-113 and Chapter 6; C Minto et al 'The effect of clitoral surgery on sexual outcome in individuals who have intersex conditions with ambiguous genitalia: a cross-sectional study' (2013) 361 Lancet 1252; and also UN Human Rights Council, above n 12, at para 77.

${ }^{53}$ This is reflected in the literature, see eg S Preves Intersex and Identity: The Contested Self (New York: Rutgers University Press, 2003).

${ }^{54}$ This criticism has been reflected in the academic literature. See, for example, Greenberg, above n 11, p 21; S Creighton 'Surgery for intersex' (2001) 94(5) Journal of the Royal Society of Medicine 218; and M Holmes 'Distracted attentions: intersexuality and human rights protections' (2005) 12 Cardozo Journal of Law and Gender 127.
} 
... there aren't enough studies that really track the longitudinal effect of intersex people who don't have their reproductive organs ... I think that's what the medical community should actually invest in given that they're doing these surgeries, and in a way, it's leaving people out in the cold ... (Respondent 15)

Not only were individuals concerned that the early timing of these interventions meant children had little voice in these matters, but many respondents were concerned that individuals and/or their parents were not fully informed or consulted by the medical profession. This finding of a lack of informed consent is being increasingly supported by other literature. ${ }^{55}$

When you are seven and you realise that your mother especially and also your father are very stressed, everybody is stressed and it has to do with your genitals, and then you consent out of wish to please or to take this stress away. Everybody knows that most children are doing things because they want to be accepted or liked or because they want to please their parents, and the doctors. (Respondent 5)

Moreover, this medical approach is also accompanied by a rhetoric of secrecy, leading to the erasure of intersex from mainstream discourse of which parents, as Respondent 7 put it, 'become complicit in [erasure] innocently': '... Doctors largely dissuade intersex people from contacting intersex support and advocacy groups rather than encourage participation' (Respondent 2). Additionally, some individuals indicated that medical records were difficult to access or were often incomplete: '... [it is very hard] to get this information that hospitals and medical professionals do not seem very willing to share it' (Respondent 8). All bar one participant stated that the fundamental concern of the intersex movement was therefore to prevent such unnecessary surgeries and in doing so directly challenge and override the medical jurisdiction: 'We need protection from irreversible, non-therapeutic medical intervention on intersex infants and children who cannot provide informed consent' (Respondent 2).

However, it was evident that this group felt unable to challenge the authority of the biomedical narrative alone and that their voices for the most part went unheard by the medical community:

... it's unbelievable to me that clinicians do not want to hear from people, from a population who has been affected. How they insist that they have done the right thing when hundreds if not thousands of people are saying, 'No, you have not,' it's mindboggling. (Respondent 4)

Many respondents felt that the intersex community lacked the resources to combat the dominance of the binary sex model perpetuated by the medical profession, which respondents stated was 'very strong, very powerful, very well-funded ${ }^{56}$ Comparatively, intersex activists, charities and organisations were unfunded, relying mostly on unpaid volunteers from a variety of backgrounds. One respondent could not take part in this project because 'we have no employed staff and work on [the organisation] in our spare time, ${ }^{57}$ Moreover, respondents indicated that mobilisation within the intersex community was difficult on account of the trauma that individuals suffered and fear of exposure.

You are very weak. You are in a very weak position and it's because most of them are traumatised and are not capable to do this work and go public. Most intersex people I know, they are really afraid that somebody knows that they are intersex, even in the family. (Respondent 5)

Additionally, many individuals may not want to challenge the medical profession as they are reliant on the provision of medicine on account of their initial medical intervention:

\footnotetext{
${ }^{55}$ See eg Jones et al, above n 52, pp 106-109.

${ }^{56}$ Respondent 15.

${ }^{57}$ Respondent 10.
} 
... when you have a child and then they do the castration when he's little and the parents really know when the child is after ten years we will need a doctor who gives us prescription for hormones. So there's also a dependency. They are dependent on the doctors and then they don't want to criticise them because there's some fear of reprisals in the background. (Respondent 6)

This type of statement highlights the complexity of the embeddedness of the intersex person as they remain reliant upon the very institution they seek to alter. Consequently, respondents viewed law as an integral part of a broader strategy to challenge this power imbalance between medicine and intersex.

... until doctors and clinicians are being sued and they feel it economically, I think that is going to have the biggest impact, that and then along with that education in the mainstream media. (Respondent 4)

\section{The fallacy of formal equality approaches}

Given that the respondents highlighted substantive rather than formal inequalities, it is perhaps unsurprising that respondents were largely critical of state approaches which only focused on formal equality. Criticisms of formal equality fell into three themes: ineffectiveness; limiting the intersex movement; and creating harm.

\section{(a) Formal equality as ineffectual}

Many respondents claimed that status-based approaches failed to tackle the day-to-day concerns of intersex people and there was a general sense that status-based reforms would be ineffectual in practice. While interviewees generally recognised the potential that third markers like ' $\mathrm{X}$ ', 'O' or 'I' on official state documentation (such as passports or birth certificates) had in terms of challenging the sex binary (and thus an important development for non-binary trans people who wish to choose a nongendered or third gender marker) the majority believed third markers were not appropriate to address specific concerns about the embeddedness of intersex people within their institutional context. Many stated third markers would be ineffective, as most intersex individuals would not actually use ' $\mathrm{X}$ ' on documents like passports.

It's not an intersex issue. Most intersex are not interested in this. (Respondent 5)

... most intersex people ... either identify as being male or female and that is reflected on the passport. (Respondent 1)

Respondents were slightly more positive about using anti-discrimination law as a vehicle for empowering intersex individuals. For some, this was simply because anti-discrimination law carried with it basic social protections in the workplace and beyond which has transformative potential in terms of the day-to-day reality of intersex embodied people:

... many people feel the need to lie in their place of work ...they might have to see doctors to deal with the ramifications of what has been done to them, for example to access hormone replacement therapy if they've faced some sort of sterilisation and often these treatments are only accessible through specialists facilitating the need to travel to see medical professionals ... For someone who doesn't have any protections in place, it doesn't feel like something you can safely share in your workplace whereas if the community knows that ok, this is protected, even if I mention it or say something that people piece together, then my job security is safe. Then that's sort of a different reality to be surviving in. (Respondent 8 ) 
Nevertheless, most respondents recognised the limited protective function of anti-discrimination law as it did not challenge, interfere with or even recognise the medical jurisdiction over intersex bodies: '[The] adoption of anti-discrimination legislation in Australia has made not the slightest difference to the human rights abuses intersex people face in that country' (Respondent 9). Indeed, the ruling in Carla (Medical Procedure) (2016) emphasised this criticism: here, despite the introduction of Australia's federal anti-discrimination law in 2013, the Australian Family Court ruled that parents can consent to cosmetic genital surgery on their infant, even where it results in sterilisation, without having to seek the court's approval. ${ }^{58}$

Some accused states of merely playing 'lip-service' to the needs of the intersex community rather than offering effective reforms. Respondents emphasised more generally that law needed to 'have teeth' to the intersex community's needs or it would be 'a waste of time, ${ }^{59}$ raising questions over whether anti-discrimination law alone will have any meaningful impact in practice. Individuals were concerned that status-provisions would have limited legal effect in practice (it was not commonplace for intersex individuals to experience discrimination in the workplace on a day-to-day basis) and consequently ignored the real material experiences of intersex individuals.

This is lip service. This protects no one... I don't know of any intersex people who've been discriminated against in the workplace because they're intersex people ... if I don't see the terms bodily autonomy, or the right to self-determination in anyone's statement of, 'We enacted this or that,' all I see is people unable to protect themselves continuing to be unable to protect themselves. (Respondent 3)

By focusing only on status, law has a superficial understanding of the intersex material experience and fails to fully understand the real issues faced by intersex embodied people. Consequently, some respondents involved in legal reform discussions in their own countries stated that they did not look towards states that had just used identity focused approaches:

We did not look so much towards anti-discrimination legislation in Australia which is on the basis of intersex status whereas we decided to take the approach of gender identity which is a very different approach because when you are getting into say protections that we want because they are of special importance to our community then we feel that is a much more holistic approach to making sure that everyone in our community will be offered these protections. There isn't the need to prove your status. (Respondent 8)

This approach was highly reminiscent of Fineman's focus on the institutional context that leads to inequality: 'Discussions about discrimination tend to focus on particular episodes or specific situations and victims, and do not necessarily incorporate an analysis of the structures in which such actions are manifested.... ${ }^{60}$ This statement encapsulates the reasons behind the majority of participants' rejection of both anti-discrimination law and third gender markers. Such an approach does not disturb the social structures that contribute to the creation of these problems. Anti-discrimination law and third gender markers fail to challenge the medical approach to intersex embodiment. Both these types of law do little to challenge this medical-construction and only offer compensation to individuals willing to engage with these legislative approaches on a case-by-case basis. Such narrow jurisdictional conceptualisations entrench a lack of resilience into the very construction of (and political possibilities around) intersex. As a consequence autonomy, rights and bodily integrity must be at the forefront of

\footnotetext{
${ }^{58}$ Carla (Medical Procedure) [2016] Fam CA 7 (20 January 2016). See M Carpenter 'The Family Court case Re: Carla (Medical procedure) [2016] Fam CA 7’ (2016) available at https://oii.org.au/31036/re-carla-family-court/ (last visited 17 July 2018) for a critique of the case.

${ }^{59}$ Respondent 7.

${ }^{60}$ Fineman (2014), above n 19, at 116.
} 
'institutional reform, not individual damages'. ${ }^{61}$ Status-based approaches are rooted in formal equality and do not ostensibly challenge the medical governance of intersex bodies, ignoring the evidence that non-therapeutic medical interventions are harmful and continue to be performed on intersex children without their consent. ${ }^{62}$ Thus, such legal approaches ignore the calls to prohibit such practices from advocacy groups, human rights organisations and supranational bodies that seek to advance towards more substantive understandings of equality. ${ }^{63}$

\section{(b) Formal equality as limiting the intersex movement: silencing infant genital mutilation (IGM) and perpetuating misunderstandings}

Respondents were concerned that by effectively entrenching this limited understanding of intersex within law, such legislation may continue to perpetuate and reinforce narrow understandings of formal equality that presume that discrimination is the only barrier to achieving equality. ${ }^{64}$ The danger is that policy-makers and society may then believe that the matter has been rectified and many respondents were concerned that this would actually strengthen the hold of the medical jurisdiction by silencing narratives and the voices that challenged the medical regulation of intersex bodies: '.. it's used to silence discussions about IGM' (Respondent 6). Not only did respondents think status-based responses were most common as they were an 'easy' quick-fix option, but some respondents believed the misplaced direction of the legislative response was also due to policy makers' lack of understanding and interest in issues faced by intersex individuals: 'For the politicians and so on, it's easy to do this registration stuff because they can say, "We have done something for the intersex. What's the problem?" (Respondent 5).

The failure to address the pressing issue of intersex surgeries was attributed by many respondents to the frequent conflation of intersex matters with other LGBT concerns. Most respondents emphasised the similarities between LGBT and intersex groups in terms of their 'overlapping concerns ... to do with the binary ideologies around sex, gender and sexuality ${ }^{65}$ and the strategies necessary to fight cultural and institutional norms. However, some respondents believed that policy makers failed to identify the specific intersex concerns, namely that children undergo early medical interventions on account of being intersex.

Sometimes policy makers deal with trans issues and believe that by doing so they are covering intersex issues as well, not realising that protections put in place that benefit trans people while they benefit part of our community it's not the grounds or key demands of our community. (Respondent 8)

This is perhaps unsurprising given that adopting the strategies and drawing analogies with other groups that are historically protected is a necessary strategy in a system where equality is constructed as anti-discrimination. ${ }^{66}$ Fineman, Fraser and others have emphasised that an anti-discrimination approach can create competition between would-be allies in the search for social justice. ${ }^{67}$ Groups have to compete for resources and can be hostile to those who attempt to draw analogies, as they may view the tactic as 'diluting' their protection through 'lesser claims' ${ }^{68}$

There is increasingly money available but it always goes for discrimination and LGBT issues. In our experience the intersex groups who define themselves as LGBT they get the funding, but groups like us who want a change in the medical practice we get shunned. (Respondent 5)

\footnotetext{
${ }^{61}$ Fineman (2014), above n 19, at 110 .

${ }^{62}$ Creighton, above n 54; Holmes, above n 54; Carpenter, above n 58.

${ }^{63}$ UN Human Rights Council, above n 12; Council of Europe, above n 12.

${ }^{64}$ Fineman, above n 25; H Collins 'Discrimination, equality and social inclusion' (2003) 66 Modern Law Review 16.

${ }^{65}$ Respondent 13.

${ }^{66}$ Fineman, above n 25, p 15.

${ }^{67}$ Fineman, above n 25, p 15. Fraser, above n 20.

${ }^{68}$ Fineman, above n 25, p 15.
} 
Fineman further critiques anti-discrimination law on the basis that identity characteristics can mask differences within groups (either based on identity or status). Participants were aware of these dangers and were particularly concerned that policymakers continuing conflation of trans and intersex issues could lead to negative consequences for intersex embodied persons. Similarly, identity-based approaches can conceal differences between groups and the general population. As Fineman notes: 'Such division can undermine political effectiveness and impede coalition building'. ${ }^{69}$ The similarities between intersex embodied persons and society in general cannot be understated, with many participants seeking to enjoy the rights (such as bodily integrity) already enshrined in law and possessed by the majority of the population, rather than creating new and unique legislation based on status. For most, problems did not arise through overt discrimination, but they instead felt that the state and its institutions created the inequalities that they faced. For Fineman, in situations of disadvantage in which overt discrimination is not an issue, the characterization of vulnerability as individualized and attached to only certain groups can obscure various forms of structural inequality. ${ }^{70}$ These statusbased approaches grounded in formal equality contribute to clashes over funding and divisions between various advocacy and activist groups. Whilst some participants were pragmatic about sharing funding with, or obtaining through the broader LGBT coalitions, others were anxious that this might erase specifically intersex concerns from the agenda. ${ }^{71}$ Others still were concerned about the use of an identity category as the basis of legal protections.

\section{(c) Formal equality as harmful}

Even more concerning, respondents emphasised that status-based approaches could actually in practice be harmful. The majority thought that using a third marker such as ' $\mathrm{X}$ ' routinely to signify intersex would expose information that many did not want to be in the public domain:

... they don't want to stick out. If they had the possibility they wouldn't use this opportunity to put an X instead of F or M ... they are really afraid that somebody knows that they are intersex, even in the family. (Respondent 5)

In fact, an automatic third marker could actually make individuals less resilient; it would further serve to 'other' intersex individuals, presenting intersex as a deviant or lesser sex, and thus ostracising individuals at both cultural and institutional levels:

The moment you start putting Os and Xs on there, it's like aren't you stigmatising a group? Are you empowering them? Are you giving them more freedom or are you taking freedom away? ... if I had an 'X' on ... my passport, I would not feel happier I think. I would not feel like I had more freedom. (Respondent 12)

Moreover, some were concerned that using a third marker to signify intersex embodied people would further distort narratives surrounding sex and intersex. A third sex approach would fail to recognise sex as a spectrum with an infinite combination of possibilities and simply lead to a tertiary system with rigid categories:

I oppose them as far as ' $\mathrm{X}$ ' includes intersex. The use of ' $\mathrm{X}$ ' for intersex establishes or reinforces a notion that intersex is not 'male' or 'female'. This is nonsense. Sex is a spectrum from male to female (or vice versa) and intersex is a blend of both. (Respondent 2)

\footnotetext{
${ }^{69}$ Fineman (2014), above n 19, at 109.

${ }^{70} \mathrm{Ibid}$.

${ }^{71}$ See, for example, recent controversy whereby an IVF company specialising in the removal of intersex traits in embryos sponsored a LGBTI event: https://oii.org.au/30555/sponsorship-elimination-intersex-traits/ (last accessed 10 July 2018).
} 
Most notably then, the respondents emphasised that a third marker should not be compulsory for intersex embodied individuals; X 'should not be predicated on having intersex anatomy'. ${ }^{72}$ Rather, third markers should be available for any individual who wished to use one. ${ }^{73}$

Similar concerns about 'othering' and 'exposure' were played out in birth certificate discussions. Consequently many respondents were highly critical of the approach adopted in Germany. In 2013 Germany became the first European state to recognise third gender markers on birth certificates. ${ }^{74}$ Section 22 of the Gesetz zur Änderung personenstandsrechtlicher Vorschriften (PersonenstandsrechtsÄnderungsgesetz-PStRÄndG) 2013 states that If the child can be assigned to neither the female nor the male sex, then the child must be entered into the register of births without such a specification'. ${ }^{75}$ This seismic change to understandings of sex and gender in Germany was undertaken without similar changes to existing anti-discrimination law or marriage law. ${ }^{76}$ Consequently, German intersex people are at an increased (rather than decreased) risk of discrimination and will, in many instances, be unable to marry. Alongside an increasing number of other states, it also permits individuals (including intersex people) to choose a third marker on passports. ${ }^{77}$ Such changes, although raising the visibility of intersex people, also serve to decrease their resilience. ${ }^{78}$

Moreover, while some respondents felt the ability to leave birth certificates blank where children were of indeterminable sex would alleviate the time pressures placed on parents. potentially preventing them from making hasty and irreversible decisions, many respondents were concerned that a blank or third marker on birth certificates would actually increase the chance of medical interventions:

... allowing a birth certificate to be filed with an indeterminate marker would give parents time and doctors time to come to rational decisions and that that would discourage surgery. There's been various fears about it, including fears that doctors will say, 'Well, I must... if you don't let me do surgery, I have to mark unknown on the birth certificate,' or that parents or doctors will rush the surgery to avoid that unknown marker. We haven't seen yet how it plays out. (Respondent 14)

Certainly, recent evidence suggests that intersex babies born in Germany after 2013 who had been registered as 'other' had had their legal sex changed to boy or girl very quickly and at the same time the number of surgical interventions on intersex babies in Germany has increased since the law was amended. ${ }^{79}$ Germany's approach may therefore be implicitly pressurising parents to place their children into the sex binary to avoid their child being categorized as ' $\mathrm{X}$ '.

Most respondents believed that sex/gender markers should be entirely removed from official documents like birth certificates and passports, ${ }^{80}$ not just for those who are intersex:

... any sort of third category on a birth certificate can, in fact, be dangerous... because it may warrant medically unnecessary intervention, so parents may authorise such procedures in

\footnotetext{
${ }^{72}$ Respondent 4 .

${ }^{73}$ This would fit the trend towards self-declaration in legal gender recognition for trans people (eg Ireland, Norway and Malta) and additionally benefit non-binary identities. For a critique of self-declaration see Dietz, above $\mathrm{n} 2$.

${ }^{74}$ Germany's Gesetz zur Änderung personenstandsrechtlicher Vorschriften (Personenstandsrechts-ÄnderungsgesetzPStR ÄndG) 2013.

${ }^{75} § 22$ Abs 3: (3).

${ }^{76}$ Travis, above $\mathrm{n} 5$, at 182 .

${ }^{77}$ See above $\mathrm{n} 36$.

${ }^{78}$ Some of these concerns may have been mitigated by a recent court ruling, which held that people claiming a third gender could utilise existing anti-discrimination law on gender (Order of 10 October 2017 - 1 BvR 2019/16).

${ }^{79}$ Amnesty International First Do No Harm; Ensuring the Rights of Children with Variations of Sex Characteristics in Denmark and Germany (London: Amnesty International, 2017).

${ }^{80}$ For an interesting discussion on this point see D Cooper and F Renz 'If the state decertified gender, what might happen to its meaning and value?' (2016) 43 Law and Society 483.
} 
order to prevent their child from being placed into any third category. To me, the bigger issue is why do we need those categories at all? (Respondent 12)

While respondents felt society was not ready to move away from sex/gender markers entirely, some respondents called for greater fluidity on birth certificates so children could amend the birth certificate if they wanted to. Participants noted that this alone, however, would not do enough to challenge the medical profession's continued use of non-therapeutic interventions. For vulnerability theorists, relationships between the state and 'vulnerable groups' based on identity politics are often enacted in two overlapping ways. The first relates to groups who are discursively (and perhaps institutionally) constructed in negative terms (such as immigrants, refugees or criminals). State intervention in these contexts consists of surveillance and regulation and can often be punitive and stigmatising. The second relates to groups seen as 'deserving' (such as the elderly or the impaired) where state responses are frequently paternalistic and also stigmatising. These two approaches are by no means exclusive and there are many instances of state regulation being paternalistic through surveillance and regulation. ${ }^{81}$ Paternalism, stigmatisation, surveillance and regulation have been the hallmarks of medical approaches to intersex embodiment. Certainly, participants were wary of paternalism, stigma and surveillance in their rejection of third gender markers. Moreover, these types of legislation highlight the dangers of focusing on formal rather than substantive equality. State constructions of intersex as a third sex through legislation fail to take into account the wishes and desires of the intersex community, the majority of which define as male or female. The next section also addresses legal identity but moves the discussion to the possible benefits of formal equality law.

\section{The transformative potential of formal equality}

While many comments regarding formal equality were negative, there was evidence of cautious optimism from respondents in relation to the potential of status-based approaches: many respondents felt that more formal mechanisms of equality could trigger more substantive changes at both a social and institutional level.

\section{(a) Formal equality: a symbolic shift}

Most notably, respondents praised status-based reforms for having instigated a symbolic shift. Status-based reform not only acknowledges the existence of intersex but also means intersex individuals would now be included in a social and legal space where before they had been absent:

It does get the term intersex in front of the public; it does force legislative bodies to engage with the material.... (Respondent 3)

Thus, the creation of this legal space was viewed by optimistic respondents as a powerful and effective starting point for meaningful change; anti-discrimination legislation had created a space for negotiation. In the Australian system, the legislation was brought in during a consultation around wideraging reforms to anti-discrimination law. In the initial construction of the Bill, intersex had been framed as a gender identity issue. Consultation spearheaded by intersex groups allowed for the legislation to be more informed and so was seen as 'opportunistic' (Respondent 16) rather than as the result of extensive lobbying. Such legal reforms were therefore commended for their potential to raise social awareness about intersex, and others acknowledged that it would now be easier to campaign for more rights in these states.

\footnotetext{
${ }^{81}$ See eg B Clough 'Vulnerability and capacity to consent to sex - asking the right questions?' (2014) 26 Child and Family Law Quarterly 371.
} 
... there are just still so many people that don't know what intersex is and therefore, so many people who are at the mercy of doctors who are misinforming them when their intersex children are born ... anything that raises the profile of the issue and just raises awareness that intersex people exist ... is relevant for sure .... In terms of getting these laws passed and getting the senate hearings they've got and things like that, they've been very effective in raising the visibility and the profile and getting government bodies on their side and that is a very important step to changing the [medical] regime. (Respondent 14)

\section{(b) Formal equality: a starting point for more substantive changes}

Moreover, despite extensive criticisms of anti-discrimination law and third markers, other respondents remained optimistic that legal recognition of intersex status may be empowering in the long term: the creation of a legal space will increase the visibility of intersex individuals at the institutional and discursive levels. Bird, for example, argues that such legal acknowledgement of intersex will not only create greater space for political negotiation, but it may create a social space for individuals to participate in if they so wish. ${ }^{82}$ This may in turn give individuals a legal platform to legitimately challenge the authority of the medical profession.

The introduction of anti-discrimination law, or indeed any status-based reform, was considered a positive 'first-step' towards a more holistic approach. Anti-discrimination law was therefore seen as the start of the challenge to the medical jurisdiction and to rectifying social inequalities in other areas. One respondent drew attention to the fact that the introduction of anti-discrimination law in both Malta and Australia had led to the creation of intersex-specific policies being developed in other fields such as education. ${ }^{83}$ Thus, while many of these 'optimists' recognised the shortfalls in terms of protection, they emphasised the fact that such reform must still be viewed as a victory:

I think I'm a big proponent of working with what we've got, and ... yeah, you can critique this, but we need to call it a victory ... this isn't the most important step. It's something that we can work with. It's something that is valuable and it's something that can give breathing room, a little breathing room to a very few people .... (Respondent 14)

\section{Challenging substantive inequalities}

Despite this optimistic theme, the respondents believed that legislative reform that embraced substantive equality was the only way to truly redress the inequalities faced by intersex embodied people.

\section{(a) Substantive equality: able to redress medical/individual power imbalance}

While there were mixed responses to a solely status-based approach, all bar one participant felt that bodily integrity was the core issue for any state-led reform. Non-therapeutic interventions on infants should be deferred until the individual was old enough to consent and fully understand the risks associated with surgery. Legal approaches grounded in identity were seen as focusing on adults at the expense of the needs of children. In this context the role of law was clear: to protect the bodies of children from non-therapeutic medical interventions. This focus on bodily integrity has been mirrored in legal research around intersex issues. ${ }^{84}$ Participants felt more safeguarding was needed with regard to surgery. They highlighted the sterilising nature of surgery and felt this ought to have judicial oversight.

\footnotetext{
${ }^{82}$ Bird, above $\mathrm{n} 17$, at 67.

${ }^{83}$ Respondent 17.

${ }^{84} \mathrm{M}$ Fox and M Thomson 'Cutting it: surgical interventions and the sexing of children' (2006) 12 Cardozo Journal of Law and Gender 81; E Grabham 'Bodily integrity and the surgical management of intersex' (2012) 18 Body and Society 1; P-L Chau and J Herring 'Defining, assigning and designing sex' (2002) 16 International Journal of Law, Policy and the Family 327; F Ammaturo 'Intersexuality and the "right to bodily integrity"; critical reflections on female genital cutting, circumcision, and intersex "normalizing surgeries” in Europe' (2016) 25 Social and Legal Studies 591.
} 
All respondents bar one believed the preferred solution was a rights-based approach that both focused on preventing surgeries and offering substantive protections to redress inequalities:

... I think it's, again, human rights issues, creating spaces, having laws that are inclusive of intersex folk, but also creating provisions in school, at work, and protections for people who are intersex. And I think as there is more visibility, that will inform more policy. But I think it's important to really... use the UN, human rights decree about the basic things that people need in order to live and to thrive .... (Respondent 15)

For many respondents, Malta offered a model of good practice for other states to follow, having brought in a suite of holistic intersex reforms in 2015 which most notably prohibits unnecessary sex assignment treatment and surgeries on minors. ${ }^{85}$ As one respondent stated, 'Malta is a beacon of hope. ${ }^{86}$

\section{(b) Substantive equality: driven by the intersex community}

Malta's legal reforms were considered so successful because policy makers had actually engaged in meaningful conversations with intersex individuals and groups, and thus the legislation was driven by the community's needs and experiences.

[Policy-makers must work] extremely closely with the community themselves. People from those communities should serve as advisors to any legislative changes that are being proposed that affect their community. These are the people who will know how the proposed policies or legislation will work in practice. (Respondent 8 )

Thus, respondents articulated the need to educate policy-makers and legislators. Many also indicated that education needed to be targeted at the medical profession and wider society; legal reform alone would not change the mistreatment of intersex embodied individuals.

[Law is] a step ... I really believe that other things have much bigger impacts. I think you have to [also] change the hearts and the minds of society ... I would like to see obligatory education for all clinicians, from sociologists, counsellors to psychologists to psychiatrists to all medical personnel and clinicians ... that's not just a two-hour lecture once in their whole training ... And along with that education of clinicians I would like to see intersex as something that is put into a school curriculum. (Respondent 4)

Despite this positivity, given how recent this reform is in Malta, the full effects are yet to be understood. In other countries medical intervention continues to be structured as an emergency, thus requiring surgical intervention early. Even where this is presented as a choice, parents are often willing to defer to medical expertise, given the discursive and institutional invisibility of intersex issues. ${ }^{87}$ Additionally, Malta permits individuals to self-determine their own gender identity (without medical evidence), ${ }^{88}$ extends its 'hate crime' legislation to incorporate sex characteristics and also sets out sex characteristics as a protected category within its anti-discrimination law. ${ }^{89}$ Thus Malta has an

\footnotetext{
${ }^{85}$ See nn $42-45$ above.

${ }^{86}$ Respondent 11.

${ }^{87}$ See eg K Karkazis Fixing Sex: Intersex, Medical Authority and Lived Experience (London: Duke University Press, 2008); Davis, above $\mathrm{n} 2$.

${ }^{88}$ GIGESC, s 4 allows individuals to change official records of their gender without requiring any medical evidence. For a critique of the ways in which self-determination of gender can be implemented see C. Dietz (forthcoming) 'Governing Legal Embodiment'.

${ }^{89}$ GIGESC, s 4 allows individuals to request change in first name and recorded gender to reflect self-determined gender. No medical evidence is necessary. Section 10(3) amends Art 83B of the Maltese Criminal Code to include offences motivated
} 
expansive approach that decouples legal regulation of intersex embodiment from the biomedical narrative and instead recognises and attempts to integrate intersex embodied people as full participants in Maltese society.

However, it is important to note that Malta's approach is not without criticisms and the intersex community has voiced concerns that its law lacks 'bite': doctors who conduct such surgeries only face a minimal fine ${ }^{90}$ and the law does not prevent parents from seeking treatment in other jurisdictions where such practices are not prohibited. Rather, the positivity is directed at Malta's broader attempt to protect bodily integrity. In contrast to third gender markers and anti-discrimination law, approaches based around bodily integrity challenge the power, knowledge and jurisdiction of medicine by removing intersex subjects from its pathologising domain. Such shifts relocate intersex embodiment away from the scope of intervention, regulation and surveillance towards equality, potentiality and resilience. This approach takes responsibility for the fact that many of the problems faced by intersex embodied people are caused by institutions and attempts to ameliorate these difficulties. Moreover, this practice encourages state responsibility for the medical profession and allows for disruptions of and negotiations around medical power and knowledge.

This paradigm shift in the substantive equality obligations of state responsibility allows for bigger questions than simply 'what jurisdiction does this fall under?', instead enabling discussions around educational reform, legal protections and changes on an institutional rather than individual level. ${ }^{91}$ Furthermore, this institutional reframing goes beyond discussions of the public/private divide. Consequently, intersex embodied persons can be protected from not only law and medicine, but also the family, the education system and other (private) networks of potential support or harm. Such an approach prevents jurisdiction being articulated in ways that prevent state responsiveness. Whilst some may question the value of placing such powers in the state's hands (that go beyond the public domain and into the private sphere), this paper would contend that the state has to be the body that responds to these issues. First, this is because such responses to intersex embodiment foreground the responsibilities of the state to all its subjects. Secondly, these responses acknowledge the role the state has played in creating the conditions for problems around intersex embodiment to occur (if not creating the problems directly). Thirdly, such an approach recognises that these are not individual issues, but are persistent, pervasive and systemic. As such, the state is central to real progress in realising substantive equality and the goals of intersex advocacy, activist and educational groups. $^{92}$

\section{Recommendations}

Accordingly we recommend the following measures to be taken by states. First and foremost, nontherapeutic medical interventions on intersex children must be prohibited until they are able to provide informed consent themselves. The importance of this finding cannot be understated and supports a growing call in medical law to ensure the protection of bodily integrity for all people. ${ }^{93}$ In turn, therapeutic treatment must be closely monitored to ensure it does not adhere to reasoning that relies upon aesthetics or normativity or present statistical information in a manner that is unduly

on the basis of gender expression and sex characteristics. GIGESC, s 14 prohibits discrimination on the basis of sexual orientation, gender identity, gender expression and sex characteristics' discrimination.

${ }^{90} € 500-€ 1000$ : GIGESC, s 11(3).

${ }^{91}$ See eg Jones et al, above n 52. See also K Roen “'But we have to do something”: surgical "correction” of atypical genitalia” (2008) 14 Body and Society 47.

${ }^{92}$ It is worth returning here to the potential ramifications on these recommendations of a lack of participants from the global south. Our participants all came from states that are 'welfarist' and relatively benign (which have strong civil societies, 'rule of law' and have moved from legal frameworks based on sexual 'wrongs' to ones based on sexual rights). Our recommendations are thus based on the assumption of substantial state capacity, which may thus limit the contexts to which they can be applied.

${ }^{93}$ Fox and Thomson, above n 84; Grabham, above n 84; Chau and Herring, above n 84; Ammaturo, above n 84. 
biased. ${ }^{94}$ Additionally, much more could be done to bring intersex embodied children and their families into contact with other intersex persons. This would provide a mixture of education and support, allowing these families to ask questions in a de-pathologised environment. This, however, would require state funding of intersex organisations or new roles to be created within the medical profession - relying on voluntary contributions would make the application of this policy unreliable and patchy. ${ }^{95}$ Secondly, educational reform is needed to combat binary understandings of sex and gender. Such an approach should highlight sex and gender as a spectrum rather than as a binary. Long-term, this strategy would destabilise constructions of non-therapeutic medical interventions as 'emergencies', allowing for a greater range of choices to be available to intersex embodied people and families alongside raising general awareness and acknowledgment of intersex concerns. At least for the medium term, children should continue to be registered as male or female, but with greater fluidity built into the legal categorisations of sex and attention paid to children's wishes and desires. ${ }^{96}$ Thirdly, anti-discrimination law can be a useful tool, but only when used in conjunction with bodily integrity. If bodily integrity is not prioritised, anti-discrimination law risks being symbolic and worse, potentially entrenches intersex embodied persons into systems of marginalisation. Consequently, where states like Germany and Australia have begun to introduce status-based reform, these must be accompanied by more holistic measures to offer any real resilience to intersex embodied people. Fourthly, third markers (on passports and birth certificates) were seen as largely unhelpful to the intersex community. Mandatory third gender markers on birth certificates for children were thought to actually lower the resilience of intersex embodied children and as such should not be an area of legislative reform. These community-informed recommendations attempt to set a new agenda for intersex reform grounded in substantive rather than formal notions of equality.

\section{Conclusion}

This paper presents the findings of the first qualitative study of the relationship between intersex embodied people and law. The timing of this study is opportune, as there is a global shift in the management and regulation of intersex embodied people away from medical models towards legal approaches. However, the ways in which legislation has sought to protect intersex embodied people has been inconsistent and achieved mixed results. Our study found that formal equality models of intersex regulation such as third gender markers on passports and birth certificates received a largely negative reception from the intersex community and were accused of being at best ineffectual and at worst potentially harmful. Many were more critical, noting that such reforms failed to address the institutional roots of the problem, pitting individuals against one another instead of focusing their attentions on the role of the state. Solely status-based reforms (as in Australia and Germany) were seen as being driven by non-intersex individuals and groups, and - in the case of mandatory third gender categories for children - as capable of entrenching vulnerability. Anti-discrimination laws (as in Australia) received mixed results.

While much of this criticism reflected concerns about formal equality, it is important to note the optimism with which many spoke: that this was a starting point, such legislation may raise the visibility of intersex concerns; a potential opening for future negotiation. Thus it may be that formal

\footnotetext{
${ }^{94}$ For example, removal of testes is often based on the likelihood of them becoming cancerous but the statistics highlight that these chances are less than the rates for breast cancer. By such reasoning all breast buds should be removed before puberty in order to prevent cancer. These arguments are not, however, mobilised against breast cancer and highlight the ways in which statistics and the power/knowledge of the medical profession are used against intersex embodied persons and their families.

${ }^{95}$ While these developments could take place through changes in healthcare policy rather than law, our respondents remain largely mistrustful of the medical profession. Moreover, 30 years of patient advocacy work has yet to lead to medical reform in this area.

${ }^{96}$ Births and Deaths Registration Act 1953.
} 
equality has a role to play in terms of instigating broader changes at a cultural and institutional level. Rather, it is where formal equality is seen by the state as being a means to an end, or the final point in achieving equality, that danger lies and the message here is clear for status-based jurisdictions: recognising intersex formally must not be seen as the end point in these discussions. The participants saw the deferment of medical interventions on children's bodies until the child could participate in the decision (alongside other reforms) as the key area for achieving substantive equality. Malta, at the time of writing, is the only state to prohibit such interventions (at least in surgical form) through law and was seen as the gold standard of institutional engagement with intersex issues. ${ }^{97}$ In part, this is because legislative developments were holistic and involved changes to the education system as well as anti-discrimination law. State responsibility for its subjects' bodily integrity trumps pathologising accounts of intersex embodiment and cuts across the public/private divide. This requires a reorientation of jurisdiction but is certainly not outside the realms of possibility. These reformulations give intersex embodiment a legitimacy that is absent within medical discourse and open up the material experiences and political possibilities available to these individuals.

\footnotetext{
${ }^{97}$ Chile has also prohibited these surgeries.
}

Cite this article: Garland F, Travis M (2018). Legislating intersex equality: building the resilience of intersex people through law. Legal Studies 38, 587-606. https://doi.org/10.1017/lst.2018.17 